\title{
Long-term monitoring of algal symbiont communities in corals reveals stability is taxon dependent and driven by site-specific thermal regime
}

\author{
Andrew C. Baker ${ }^{1,2, *}$, Tim R. McClanahan' ${ }^{2}$, Craig J. Starger ${ }^{3,4}$, Roxane K. Boonstra ${ }^{1}$ \\ ${ }^{1}$ Division of Marine Biology and Fisheries, Rosenstiel School of Marine and Atmospheric Science, University of Miami, \\ 4600 Rickenbacker Cswy., Miami, Florida 33149, USA \\ ${ }^{2}$ Marine Program, Wildlife Conservation Society, 2300 Southern Boulevard, Bronx, New York 10460, USA \\ ${ }^{3}$ Division of Invertebrate Zoology, National Museum of Natural History, Smithsonian Institution, \\ 10th Street NW and Constitution Avenue NW, Washington, DC 20530, USA \\ ${ }^{4}$ Science and Technology Policy Fellowships, Center of Science, Policy and Society Programs, American Association for \\ the Advancement of Science, 1200 New York Avenue NW, Washington, DC 20005, USA
}

\begin{abstract}
Survival trajectories for coral reefs under climate change may depend in part on shifts in the composition of their algal symbiont communities (Symbiodinium spp.). Shifts favoring thermotolerant symbionts have been recorded in response to mass bleaching events but rarely tracked through time. A $10 \mathrm{yr}$ monitoring study of Symbiodinium in a variety of Kenyan corals assessed their variability through time, across coral taxa and between sites, and their relationship to environmental conditions. Coral genera varied significantly in their propensity to host thermotolerant symbionts of Symbiodinium clade D, with some genera becoming dominated by clade D at annual maximum temperatures of $32^{\circ} \mathrm{C}$ but others showing clade $\mathrm{D}$ only rarely at $35^{\circ} \mathrm{C}$. High annual maximum temperatures, high standard deviation, positive skewness and positive kurtosis characterized sites where clade D was common. In corals whose symbiont communities were thermally labile (e.g. Pocillopora) an increase in maximum annual temperature from 30 to $35^{\circ} \mathrm{C}$ resulted in 3- to 4 -fold increases in dominance by clade D. There was no directional change in symbiont communities over the study period, but there was evidence for a $\sim 6$ yr decline in the incidence of mixed $(\mathrm{C}+\mathrm{D})$ communities following the 1998 bleaching event. These data illustrate how acute and chronic thermal stress caused by oceanographic and tidal oscillations interact to produce highly dynamic symbiotic communities. The clade D niche is a function of the environment and host taxon and, through a variety of mechanisms, is expected to expand with climate warming. Corals from warm and variable conditions represent conservation priorities because they establish a niche for these symbionts in contemporary reef environments.
\end{abstract}

KEY WORDS: Acclimatization · Adaptation · Adaptive bleaching hypothesis · Community change · Indian Ocean · Symbiosis

\section{INTRODUCTION}

The potential for adaptation and acclimatization of reef corals to rising temperatures is a critical but controversial question in contemporary coral reef science and conservation. Although there are a number of mechanisms by which corals, dinoflagellates Symbiodinium spp., and other symbiotic partners might respond to climate change (Gates \& Edmunds 1999, Rosenberg et al. 2007, Baird et al. 2009, Fitt et al. 2009), most research has focused on whether or not corals are able to flexibly associate with diverse algal 
symbionts the different physiologies of which provide greater resistance to environmental extremes (Glynn et al. 2001, Baker et al. 2004, Rowan 2004, Berkelmans \& van Oppen 2006, Jones et al. 2008, LaJeunesse et al. 2009, Oliver \& Palumbi 2009, 2011). While changes within colonies have attracted the most attention, differential reproduction and survival of colonies and species with different symbiont associations is likely to be another important factor driving population- and community-level changes (Baker et al. 2004, LaJeunesse et al. 2008).

Several studies have shown that, following heatinduced bleaching, corals can experience shifts in their symbiont communities to favor Symbiodinium in clade $\mathrm{D}$, some common members of which (notably D1 and D1a) impart greater thermal tolerance to their coral hosts (Glynn et al. 2001, Rowan 2004, Berkelmans \& van Oppen 2006, Jones et al. 2008, LaJeunesse et al. 2009). However, the longevity of these shifts, and the mechanisms that underlie them, are not well understood, and few studies have monitored coral hosts and symbiont communities over the timescales needed to assess the sustained ability of reef corals to acclimatize or adapt to continued climate change.

The few colony-level monitoring studies of bleached scleractinian corals that have been undertaken to date have found a variety of responses. Some studies found no change in response to thermal bleaching (Stat et al. 2009a), while others have found changes followed by rapid reversions back to the original communities within weeks to months (LaJeunesse et al. 2009). Others have documented change with no reversion over 9 mo (Toller et al. 2001), or slow reversion over several years (Thornhill et al. 2006). However, with the exception of work in the Florida Keys and Bahamas by Thornhill and colleagues $(2006 a, b)$, the goal of the studies has been to monitor the effects of acute disturbance on symbiont communities, rather than assess their stability over long periods in the absence of acute disturbance. Distinguishing whether reef coral communities can respond to chronic changes over long timescales in the same way that individual colonies can respond to acute disturbance is a key question in understanding the response to climate change (Hoegh-Guldberg \& Bruno 2010).

A critical issue underlying whether compensatory changes in algal symbiont communities can occur and be maintained is the degree to which specificity in coral-algal symbiosis limits the range of partnerships. This is true regardless of whether the changes occur at the coral colony, population, or community level. If coral species are generally constrained to hosting particular symbiont types regardless of environment, and there is little intraspecific variation in this association, then changes in symbiont communities occurring as a result of disturbance are unlikely to be long-lived (HoeghGuldberg et al. 2007). Consequently, the coral host in question may be unlikely to benefit from these unstable partnerships in the long-term (Stat \& Gates 2011). On the other hand, there may be strong interactive effects, where symbiont niches are not exclusively determined by coral host taxon but instead rely on environmental factors to differentiate symbiont niches within particular coral species (Rowan \& Knowlton 1995, Rowan et al. 1997, Baker 2003). In these cases, changes in the environment will lead to changes in the realized niches of symbionts on reefs, in turn affecting the frequency of symbiont types within colonies. Similarly, if changes in the environment result in differential mortality of coral genotypes within populations, or coral species within communities, then differences in symbiont specificity will also lead to changes in the frequency of different symbionts on reefs.

Physiological tradeoffs may also limit the capacity for corals to respond to climate change through shifts in their symbiont communities. Symbionts in Symbiodinium clade $\mathrm{D}$ that impart thermal tolerance have been shown to decrease the amount of translocated photosynthate (Cantin et al. 2009) and depress growth rates (Little et al. 2004, Jones \& Berkelmans 2011). These detrimental effects may not be compensated for by their increased survival during thermal anomalies. Such tradeoffs between reduced population growth and increased survival could compromise the competitive ability of affected corals in some environments. However, if changes in symbiont communities result in a net increase in the inclusive fitness of a coral host (despite potentially detrimental effects on population growth rates), then long-term shifts in symbionts might still be adaptive and favored under some conditions. Such uncertainties can only be resolved by monitoring symbiont communities over long time periods and under different environmental conditions.

This study represents the results of a $10 \mathrm{yr}$ monitoring study at multiple sites with variable environmental histories along the Kenyan coast of the western Indian Ocean. We tracked the relative frequency of one group of symbionts (Symbiodinium in clade D) in a variety of coral hosts over this timeframe. The most common members of this group are relatively resistant to high-temperature stress and may have 
increased in abundance on these reefs following the 1998 bleaching event in the western Indian Ocean (Baker et al. 2004). We tested the hypothesis that coral taxon, site, thermal environment, and time influence the abundance of dominant symbiont clades. The temperature history at each site was evaluated to determine which temperature metrics were most strongly associated with the frequencies of the different clades. This study represents the longest continuous Symbiodinium monitoring effort reported to date (2000 to 2010), and, while it takes place in an area that was severely affected by a major bleaching event prior to its initiation (1998), it covers a timeframe that has largely escaped other major acute climate disturbances, providing an opportunity to evaluate the variability of symbiont communities over time and to identify the environmental and taxonomic axes that define niches for the different symbiont taxa in this region.

\section{MATERIALS AND METHODS}

\section{Study sites}

Kenya's southern fringing reef is a nearshore shallow reef that is $<3 \mathrm{~km}$ from shore and has a maximum seaward depth of $15 \mathrm{~m}$ and a more shallow lagoon of $<3 \mathrm{~m}$ at low tide. Samples were taken from corals in the back reef environment where corals intermix with sand and seagrass. Kenyan reefs have a semidiurnal tide, with a maximum spring tide range of $4 \mathrm{~m}$ that creates considerable tidal and temperature variability in these back reef environments (McClanahan \& Maina 2003). There is also a strong monsoonal seasonal cycle that creates a warm and potentially stressful temperature environment from November to April (McClanahan 1988). The 4 reef areas in this study (Vipingo, Kanamai, Mombasa, and Diani) have different reef heights, which change tidal exposure regimes and influence water temperature variability at each site (Fig. 1).

\section{Laboratory identification of algal symbionts}

Coral tissue samples were haphazardly collected at depths of 2 to $3 \mathrm{~m}$ from the same $30 \times 30 \mathrm{~m}$ area around permanently established temperature gauges at each site. Because the focus was on community-level changes at these sites, no effort was made to sample repeatedly from the same colonies. Samples were removed from massive morphologies, such as massive Porites, using a hammer and a hollow steel punch to remove a core $\sim 5 \mathrm{~mm}$ deep and $\sim 0.5 \mathrm{~cm}^{2}$ in area. Samples from branching or frondose morphologies, such as branching Porites, Pocillopora, Acropora; and Pavona, were removed by
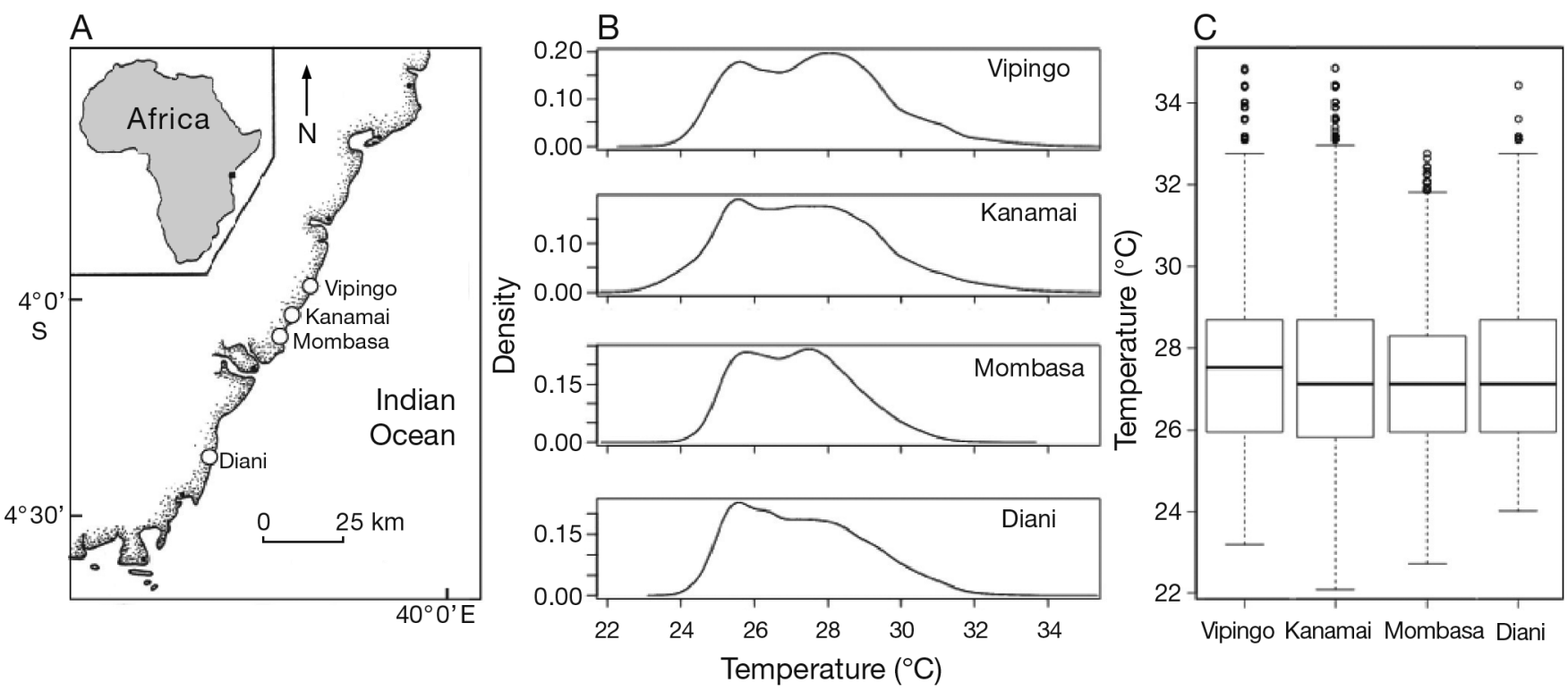

Fig. 1. (A) Map of the 4 study sites along the east African coastline of Kenya. (B) Probability density functions for temperature data obtained from in situ loggers for each study site from 2000 to 2010 . Common features of the temperature regime at these sites include bimodality, positive skewness (in favor of higher temperatures), and platykurtosis (long tails). (C) Box and whisker plots showing temperature metrics for each study site. Heavy horizontal line shows the median value; the box represents the interquartile range $(\mathrm{IQR})$; the whiskers depict the data $<1.5 \times \mathrm{IQR}_{i}$ the circles represent outliers $(>1.5 \times \mathrm{IQR})$ 
snapping off the distal ends of branches or plates (1 to $2 \mathrm{~cm}^{2}$ area). Sampling was relatively nondestructive, and tissue typically re-grew over exposed skeleton within a few weeks. In total, 743 samples were successfully analyzed for the period 2000 to 2010 (Table S1 in the supplement at www. int-res.com/articles/suppl/m479p085.pdf). Samples were preserved in saline DMSO (Seutin et al. 1991) or $95 \%$ ethanol.

Samples were processed by airbrush-blasting tissue from samples and extracting DNA from these blastates. Symbiodinium DNA was purified and analyzed using conventional organic protocols (Rowan \& Powers 1991, Baker et al. 1997) and internal transcribed spacer-2 (ITS-2) ribosomal DNA (rDNA) amplified using PCR (LaJeunesse 2001). Denaturing gradient gel electrophoresis (DGGE) was used to analyze these amplified products and distinguish mixed symbiont communities (LaJeunesse 2001, 2002).

DGGE-based assays of ITS-2 diversity have high taxonomic resolution and can readily distinguish closely related Symbiodinium types. However, potential intragenomic variation can make characterization of symbiont communities difficult when multiple, closely related sequences are present in the same sample (Stat et al. 2011), as was the case in Kenya. For this reason we analyzed samples to the clade level only to test hypotheses regarding the persistence and distribution of Symbiodinium in clade D. We used known patterns of D1a (LaJeunesse 2002), also referred to as D-1-4 (LaJeunesse et al. 2010), as our reference for all clade D assignments; no other D-types were detected in our dataset. Since substantial phenotypic variability may exist within clades (Savage et al. 2002, Tchernov et al. 2004, Baird et al. 2007), this approach undoubtedly obscures some emergent patterns at finer taxonomic scales within clade C (e.g. LaJeunesse et al. 2010). However, the principal question addressed here is the relative frequency and persistence of Symbiodinium D1a (D-1-4) as a symbiotic generalist that imparts thermotolerance. Pooling all clade $\mathrm{C}$ types allows this question to be addressed without needing to resolve intragenomic variants or distinguish species boundaries within this complex group (Correa \& Baker 2009, Sampayo et al. 2009, Stat et al. 2009b, 2011, LaJeunesse et al. 2012).

Although DGGE has high taxonomic resolution, its relatively low numerical resolution limits its ability to detect symbionts that are not dominant members of the community. Symbionts that represent $<5$ to $10 \%$ of the community are typically not detected by
DGGE, although this depends on the particular ITS-2 variants involved (Thornhill et al. 2006, LaJeunesse et al. 2008). For this reason, we categorized samples in which only clade $\mathrm{C}$ or D symbionts were detected as ' $\mathrm{C}$ dominant' or 'D dominant', respectively, and recognize that additional diversity is likely to be found in these samples using techniques with lower detection limits, such as quantitative PCR (Baker \& Romanski 2007, Correa et al. 2009, Mieog et al. 2009, Cunning \& Baker 2012, Silverstein et al. 2012). Samples in which both clades were detected using DGGE were classified as ' $\mathrm{C}+\mathrm{D}$ mixed communities'.

\section{Temperature measurements}

The study evaluated temperature variables at the study sites from field gauge and satellite measurements. Temperature gauges (Hobo temperature gauges-Onset Corporation, accuracy of $0.35^{\circ} \mathrm{C}$ at $25^{\circ} \mathrm{C}$ ) were established at each of the study sites between 1991 and 2009, and water temperatures were recorded at 1 to $3 \mathrm{~h}$ intervals. Gauges were placed in shallow water ( 0.3 to $1.0 \mathrm{~m}$ at low tide), covered in black plastic, and embedded in masonry cement to avoid the effects of light. Gauges were retrieved annually, downloaded, and average annual measurements per site were calculated (Table 1). For comparison, satellite temperature data of $4 \times 4 \mathrm{~km}$ resolution for each site over the study period were retrieved from the NOAA website.

\section{Data analyses}

The frequencies of clades D, C, and C + D in sampled coral colonies were plotted for site, time, and coral taxa. To detect significant differences in symbiont frequencies among coral taxa, we used a multivariate nominal Chi-squared frequency test, implemented in JMP (Sall et al. 2001). Differences in the frequency of the symbiont types were tested sepa-

Table 1. Mean annual water temperature parameters for the period 2000 to 2010 obtained from in situ gauges deployed at sites along Kenya's coastline

\begin{tabular}{|lcccccc|}
\hline Site & Min & Max & Mean & SD & Skew & Kurtosis \\
\hline Kanamai & 23.83 & 33.91 & 27.56 & 1.81 & 0.61 & 0.06 \\
Vipingo & 24.28 & 33.34 & 27.60 & 1.61 & 0.49 & -0.05 \\
Diani & 24.45 & 33.04 & 27.39 & 1.64 & 0.40 & -0.61 \\
Mombasa & 24.64 & 31.07 & 27.34 & 1.23 & 0.29 & -0.55 \\
\hline
\end{tabular}


rately for differences among all coral taxa and for the 4 dominant taxa (Acropora, Pavona, Pocillopora, and Porites). From the temperature data obtained from field gauges and NOAA satellite data sources, annual mean temperature metrics of mean, standard deviation, minimum, maximum, skewness, and kurtosis were calculated for the year prior to sampling (1 January to 31 December). We used these variables in a step-wise nominal regression analysis to determine the temperature variables that were the best predictors of the frequency of the dominant symbiont clades. The strength of the bivariate temperature and clade relationships were explored prior to entering the temperature variables in the stepwise procedure; variables were then entered from the strongest to the weakest. Finally, a nominal logistic fit was applied to model the relationship between symbiont clade distribution and the strongest temperature variable identified by the step-wise nominal regression analysis.

\section{RESULTS}

\section{Distribution of symbionts}

Symbiodinium in clade C represented the dominant symbionts in reef corals at the study sites overall, with clade D being dominant in the (poorly sampled) years 2000 and 2010, and less abundant in the interim years (Fig. 2). Mixed communities of Symbiodinium C + D were found in low to moderate abundance in the early sampling years (2000 to 2004) but were uncommon afterwards. Clade $\mathrm{C}$ was most common in Mombasa, followed by Diani, Vipingo, and Kanamai (Fig. 3). Clade D was consistently found in more than half of the coral colonies in Kanamai. Clade C (specifically C15) was the dominant symbiont in Porites, with only one 2001 sample containing clade D. However, other families were more variable, with clade D occurring frequently in the families Agariciidae and Pocilloporidae (Fig. 4). The families Faviidae, Oculinidae, and Acroporidae were more variable and not sampled consistently across years.

When testing for differences between taxa (genera), site, and time separately, there were statistically significant differences among all variables. However, when testing these factors simultaneously for all samples, genus was the most significant single factor $(p=0.015)$. Genus interacted very strongly with site $(p=0.002)$, site and year interacted weakly, and the overall model was relatively powerful $\left(R^{2}=0.57\right)$ (Table 2). When reducing the analysis to the 4 dominant genera (Acropora, Pavona, Pocillopora, Porites; $\mathrm{n}=683$ ), genus was again the most significant factor and interacted strongly with site $(\mathrm{p}<0.0001)$, site and year was marginal $(p=0.055)$, and the power of all factors combined was also high $\left(R^{2}=0.54\right)$ (Table 3$)$.

\section{Associations with temperature variables}

Stepwise logistic regression of temperature variables with the frequencies of the clades revealed a number of significant but weak factors (Table 4). Temperature variables obtained directly from field gauges (Fig. 1) delivered significantly better predictive value than temperatures obtained from satellites, which were not significant. Mean temperature was not a significant predictor, but most measures of temperature variation were significant. Maximum annual temperature in the year before sampling was the most significant factor in predicting symbiont dis- 


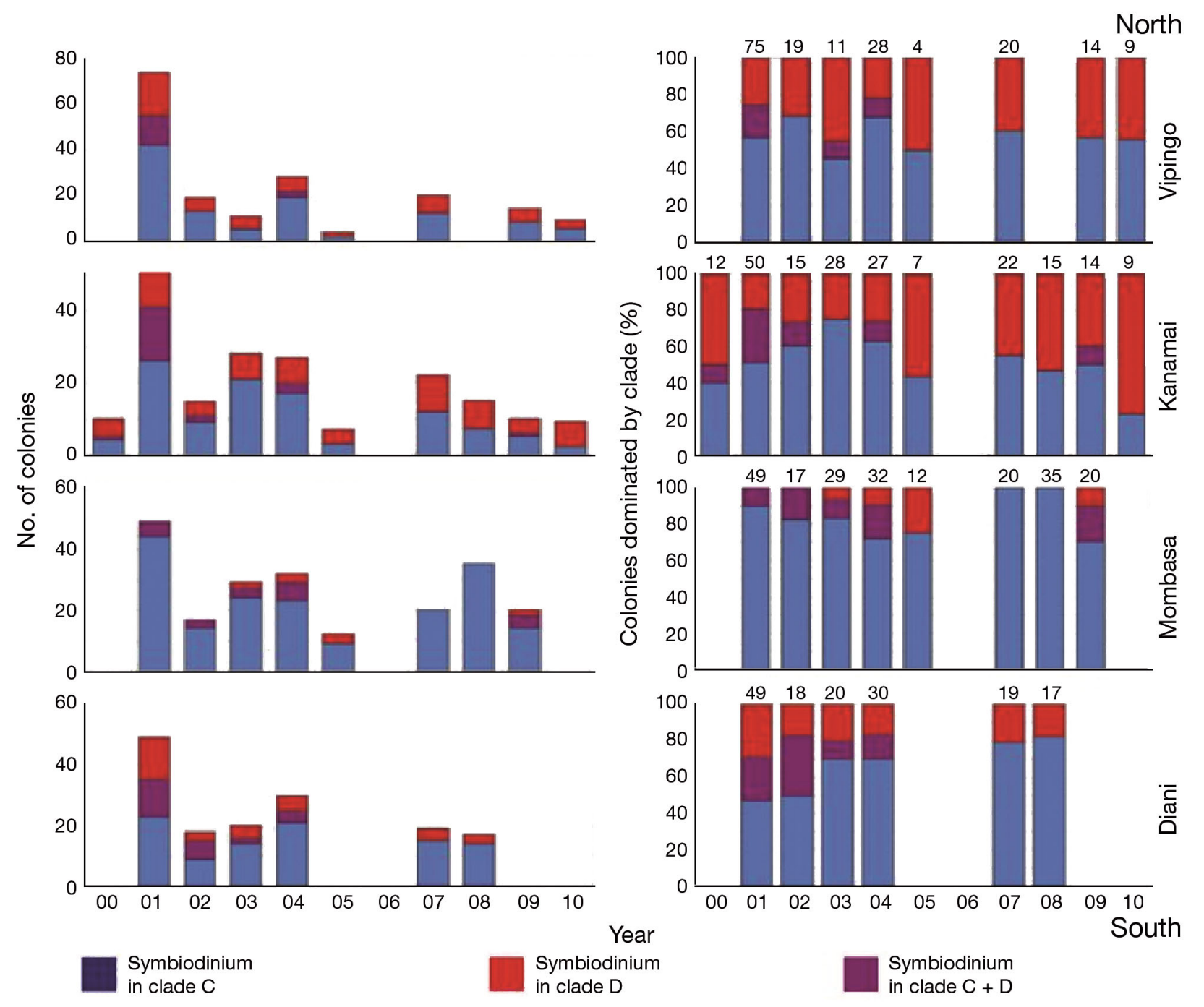

Fig. 3. Distribution of Symbiodinium clades for 2000 to 2010 at each of the 4 study sites, pooling all taxa (N = 743). Sites are ordered from north (top of figure) to south (bottom of figure). Left-hand panels show the number of colonies in each year hosting clade $\mathrm{C}$, clade D or a mixture of clades C + D. Right-hand panels show the same data as a percentage of the colonies sampled each year, with the sampling effort (no. of colonies $\mathrm{yr}^{-1}$ ) included at the top of each column

Table 2. Results of the logistic model testing for the effects of taxa, site and time on the frequency of the symbiont clade groups $\mathrm{C}, \mathrm{D}$, and $\mathrm{C}+\mathrm{D}$ for all samples; $\mathrm{R}^{2}=0.57, \mathrm{n}=741$

\begin{tabular}{|lcccc|}
$\begin{array}{l}\text { Whole model test } \\
\text { Model }\end{array}$ & -LogLikelihood & df & $\chi^{2}$ & $\mathrm{p}$ \\
\hline Difference & 360.26 & 104 & 720.53 & $<0.0001$ \\
Full & 273.02 & & & \\
Reduced & 633.29 & & & \\
Individual factors and interactions & effect likelihood ratio tests \\
Source & $\mathrm{df}$ & $\chi^{2}$ & $\mathrm{p}$ & Conclusion \\
\hline Genus & 26 & 44.09 & $<0.015$ & Significant effect \\
Site & 8 & 0.00 & $<1.0$ & Not significant \\
Year & 2 & 0.00 & $<1.0$ & Not significant \\
Genus $\times$ Site & 50 & 83.59 & $<0.002$ & Strong interaction \\
Genus $\times$ Year & 12 & 19.32 & $<0.081$ & Marginal \\
Site $\times$ Year & 6 & 13.78 & $<0.032$ & Weak interaction \\
\hline
\end{tabular}

Table 3. Results of the logistic model testing for the effects of taxa, site and time on the frequency of the symbiont clade groups $\mathrm{C}, \mathrm{D}$, and C + D for Acropora, Pavona, Pocillopora, and Porites; $\mathrm{R}^{2}=0.54, \mathrm{n}=685$

\begin{tabular}{|c|c|c|c|c|}
\hline \multicolumn{5}{|c|}{ Whole model test } \\
\hline Model $\quad-$ & -LogLikelihood & df & $\chi^{2}$ & $\mathrm{p}$ \\
\hline Difference & 313.80 & 61 & 627.60 & $<0.0001$ \\
\hline Full & 268.58 & & & \\
\hline Reduced & 582.39 & & & \\
\hline \multicolumn{5}{|c|}{ Individual factors and interactions - effect likelihood ratio tests } \\
\hline Source & df & $\chi^{2}$ & $\mathrm{p}$ & Conclusion \\
\hline Genus & 8 & 44.49 & $<0.0001$ & Significant effect \\
\hline Year & 2 & 0.00 & $<1.0000$ & Not significant \\
\hline Site & 8 & 0.00 & $<1.0000$ & Not significant \\
\hline Genus $\times$ Site & 28 & 72.05 & $<0.0001$ & Strong interaction \\
\hline Genus $\times$ Year & 8 & 11.33 & $<0.184$ & Not significant \\
\hline Site $\times$ Year & 7 & 13.78 & $<0.055$ & Marginal \\
\hline
\end{tabular}



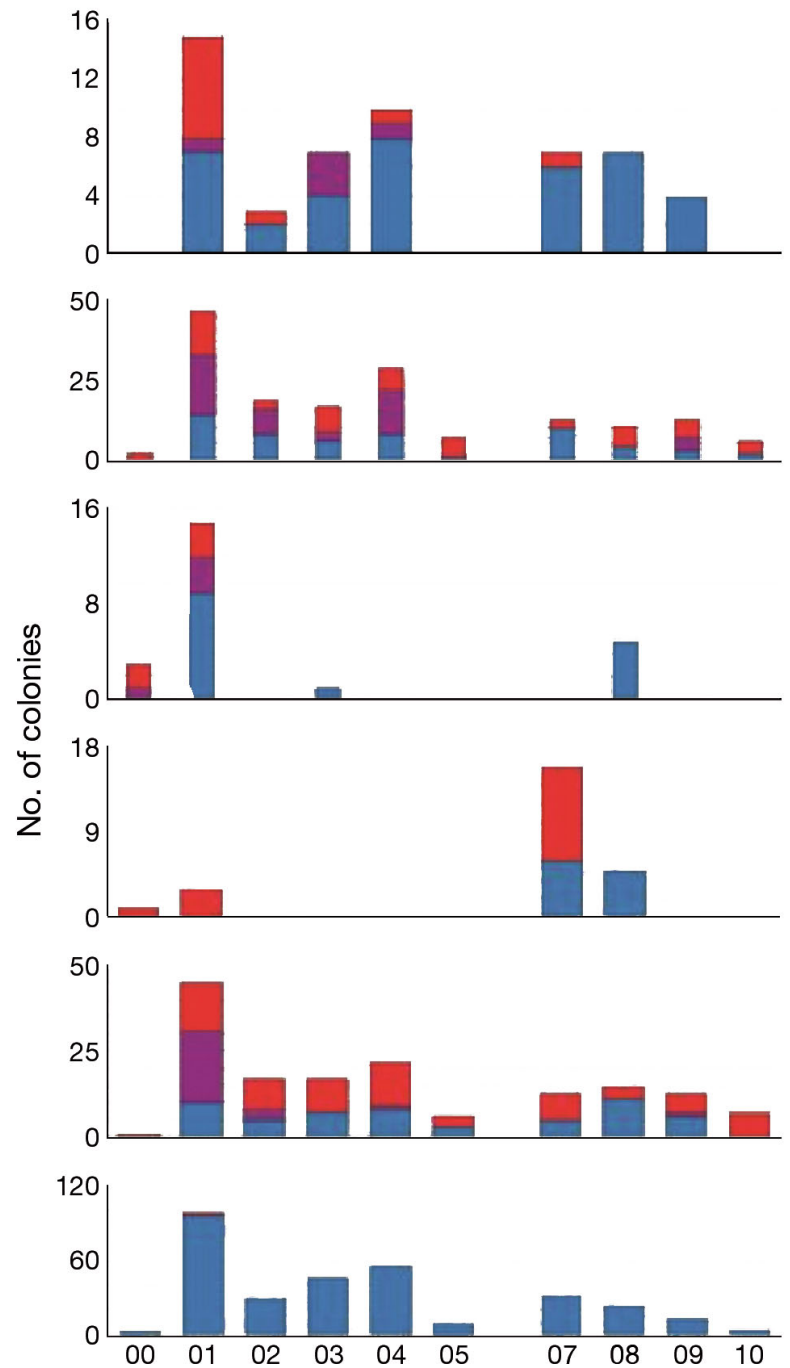
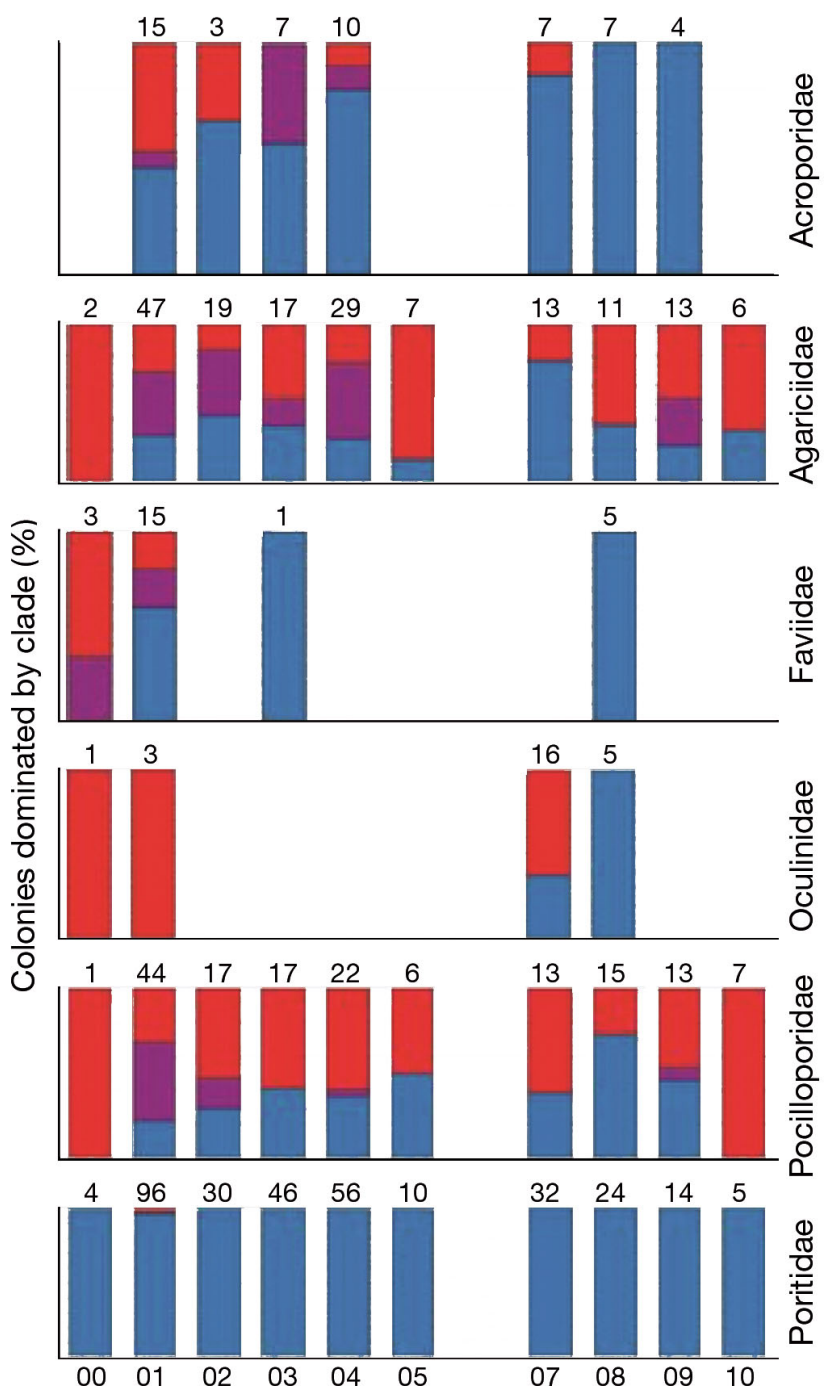

Fig. 4. Distribution of Symbiodinium clades for 2000 to 2010 for the 6 most common coral families, pooling all sites (n = 738). Left-hand panels show the number of colonies in each year hosting clade C, clade D or a mixture of clades C + D. Right-hand panels show the same data as a percentage of the colonies sampled each year, with the sampling effort (no. of colonies $\mathrm{yr}^{-1}$ ) included at the top of each column

tributions at the level of clade $(\mathrm{p}<0.0001)$, followed by minimum annual temperature in the year before sampling $(p=0.006)$, and the standard deviation of temperature in the year of sampling $(\mathrm{p}=0.02)$.

A nominal logistic fit of Symbiodinium clade for all sites and taxa pooled found that the maximum annual temperature was highly significant $(p<0.0001)$, but a weak predictor of the clade distributions $\left(\mathrm{R}^{2}=\right.$ 0.04) (Fig. 5). A $5^{\circ} \mathrm{C}$ increase in maximum annual temperature (from 30 to $35^{\circ} \mathrm{C}$ ) resulted in a 3- to 4-fold increase in the number of colonies dominated by Symbiodinium in clade $\mathrm{D}$, with no change in the number of colonies containing mixtures of clades $\mathrm{C}$ and $\mathrm{D}$.

The influence of temperature and taxa was explored by taxon-specific analyses (Fig. 6). All genera showed similar patterns, but only the symbiont communities of Pocillopora and Porites were significantly associated with maximum annual temperatures $(p<0.0001$ and $p=0.037$, respectively). In these 2 genera, maximum annual temperature was a much better predictor of Symbiodinium distribution than for the pooled dataset $\left(\mathrm{R}^{2}=0.30\right.$ and $\mathrm{R}^{2}=$ 0.17 , respectively, compared to $\mathrm{R}^{2}=0.04$ ). Clade $\mathrm{D}$ in Pocillopora was the most strongly associated with maximum temperatures, with very few colonies containing detectable Symbiodinium in clade D when maximum temperature was $30^{\circ} \mathrm{C}$, but nearly all colonies containing detectable clade $\mathrm{D}$ and the majority containing only clade $\mathrm{D}$ when maximum temperature reached $34^{\circ} \mathrm{C}$. 
Table 4. Statistical results of the stepwise logistic regression model for the variables obtained from temperature gauges and the frequency of clades C, D, and C + D. LogLikelihood $=601.1$, $\mathrm{R}^{2}=0.049$. NS: not signifcant. ndf: number of df

\begin{tabular}{|lcccc|}
\hline Parameter & Estimate & ndf & Wald/Score & $\mathrm{p}$ \\
\hline Intercept [C+D] & 3.86 & 1 & 0.00 & $<1.00$ \\
Intercept [D] & 4.47 & 1 & 0.00 & $<1.00$ \\
Maximum & -0.61 & 1 & 6.66 & 0.01 \\
Minimum & 1.05 & 1 & 7.63 & $<0.006$ \\
Average & -0.43 & 1 & 1.20 & $\mathrm{NS}$ \\
SD & 2.54 & 1 & 5.11 & $<0.023$ \\
Skewness & -1.65 & 1 & 3.77 & $<0.052$ \\
Kurtosis & 0.73 & 1 & 2.96 & 0.085 \\
& & & & \\
\hline Step history & Step parameter & $\chi^{2}$ & $\mathrm{p}$ & $\mathrm{R}^{2}$ \\
\hline 1 & Maximum & $<42.34$ & 0.0001 & 0.03 \\
2 & Minimum & $<7.51$ & 0.006 & 0.04 \\
3 & Average & $<2.39$ & 0.121 & 0.04 \\
4 & SD & $<5.34$ & 0.021 & 0.05 \\
5 & Skewness & $<0.96$ & 0.327 & 0.05 \\
6 & Kurtosis & $<2.85$ & 0.091 & 0.05 \\
\hline
\end{tabular}

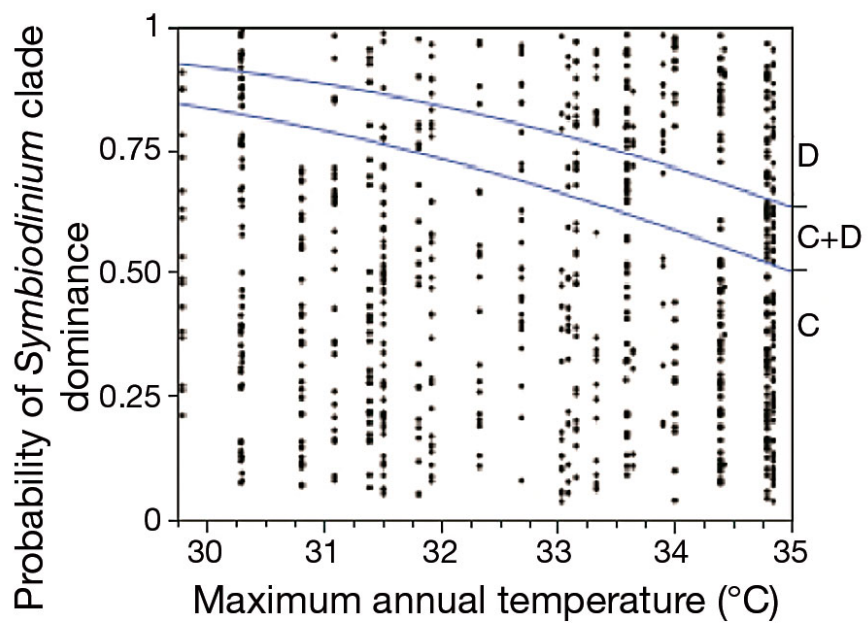

Fig. 5. Nominal logistic fit of Symbiodinium clade in shallow Kenyan scleractinian corals (all coral taxa pooled), against maximum annual temperature from in situ gauges in the year of sampling for all taxa. Curves represent the probability of assignment to Symbiodinium categories, with the area below the lowest curve representing the probability of assignment to clade $\mathrm{C}$, the area above the highest curve representing the probability of assignment to clade D, and the balance of probabilities (area between upper and lower curves) representing the probability of assignment to a mixture of clades C + D. Points represent individual colonies randomly scattered within categories to indicate sample size (expected number of colonies in each Symbiodinium category). Higher temperatures are associated with higher incidence of colonies dominated by clade $\mathrm{D}\left(\mathrm{R}^{2}=0.04, \mathrm{p}<0.0001\right)$

\section{DISCUSSION}

\section{Influence of location, time, and temperature on specificity in coral-algal symbiosis}

There were clear taxon-specific differences in symbiont communities, with genus being the most significant factor in explaining variability in the symbiont clade data. Although site and year were significant on their own, when tested simultaneously with genus, they were not significant. This was true both for all coral taxa sampled, as well as for the 4 dominant coral genera. However, the relatively strong interactions between genus and site, and the relatively weak interactions between genus and year, indicate that the effect of specificity on symbiont distributions is itself influenced by location and time.

The proximate causes underlying the interaction with genus and site are suggested by analysis of the temperature data collected from in situ gauges. Bivariate relationships and stepwise regression analysis show that maximum, minimum, mean, and standard deviation all contribute significantly to the model, although their overall contribution is relatively weak $\left(\mathrm{R}^{2}=\right.$ 0.05). Nominal logistic fits of clade distribution against mean maximum temperature illustrate the relationship between symbiont clade and mean maximum temperature (Fig. 5), and how it varies among coral taxa (Fig. 6). Predictive power was generally higher using this approach, although trends were not significant for all taxa. For example, the modeled threshold maximum annual temperature at which clade $\mathrm{D}$ becomes a common dominant varies from $\sim 32^{\circ} \mathrm{C}$ in Pocillopora to $>35^{\circ} \mathrm{C}$ in Porites (although there was only 1 occurrence of clade D in this genus in our dataset, at Vipingo in August 2001, a site with a mean maximum annual sea-surface temperature of $34.2^{\circ} \mathrm{C}$ ).

These findings support the hypothesis that coral specificity contracts niche space for Symbiodinium clade D among different hosts, although the niche may never disappear entirely (as indicated by the single colony of Porites dominated by clade $\mathrm{D}$, see also Silverstein et al. 2012). We can rank different coral hosts in their propensity to host clade D at high temperatures as follows: Pocillopora $=$ Galaxea $>$ Pavona $>$ Acropora > Porites. Coral genera at the high end of this ranking (e.g. Pocillopora) are the most 


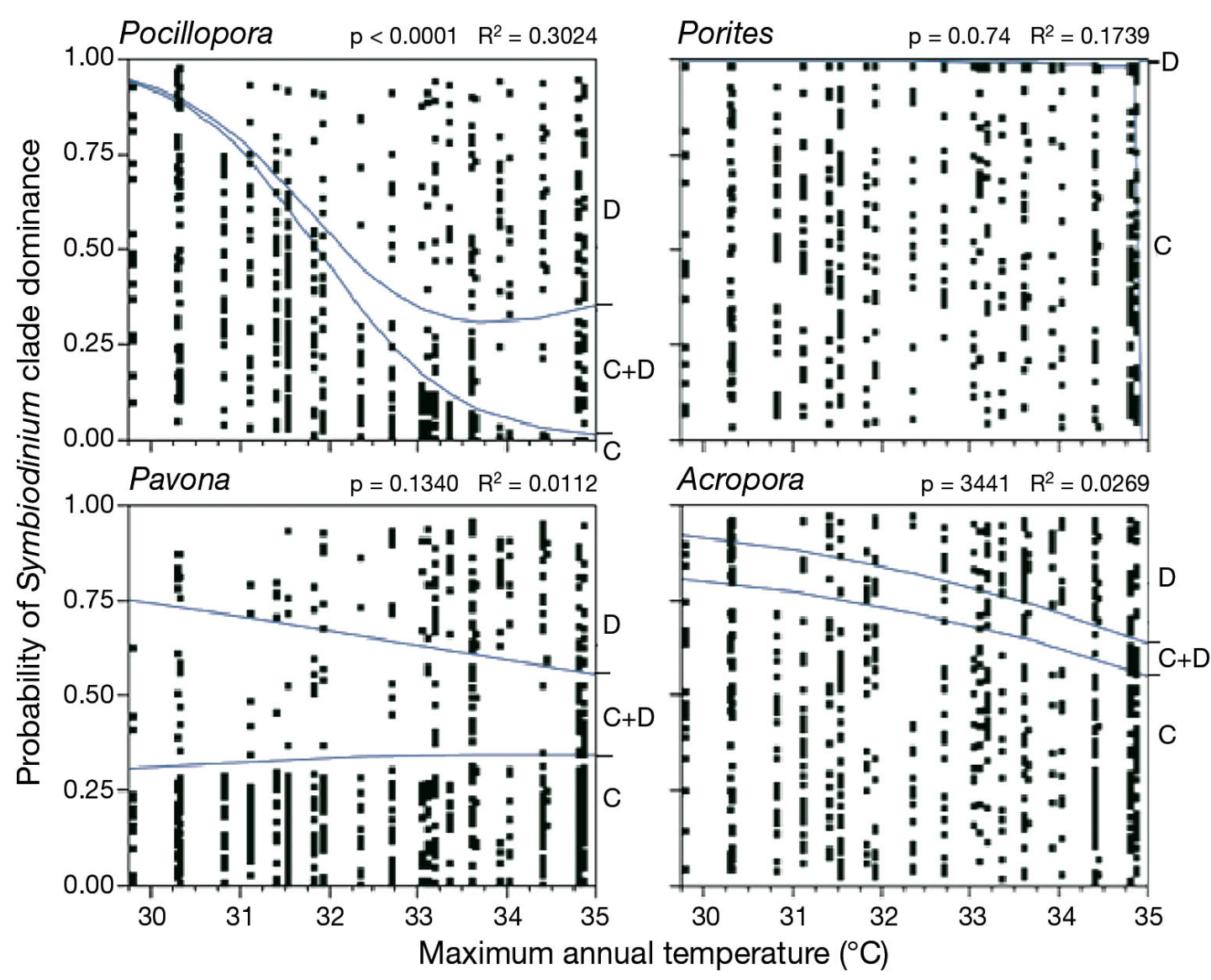

Fig. 6. Nominal logistic fit of Symbiodinium clade against maximum annual temperature from in situ gauges in the year of sampling, for the 4 most commonly sampled coral genera (Acropora, Pavona, Pocillopora and Porites). Curve properties are explained in Fig. 5. Higher temperatures tend to drive higher incidence of colonies dominated by clade D, and this trend is most pronounced in Pocillopora

'thermally labile' taxa (defined here as those most likely to experience changes in their symbiont communities in response to temperature changes over space and time). Thermal lability in symbiont communities may be one axis for identifying taxa with the highest capacity for adaptation/acclimatization, although it is only one factor among a complex suite of traits that might contribute to identifying 'winners' and 'losers' in a climate change context (Baird et al. 2009, Oliver \& Palumbi 2011), and may also be subject to costly tradeoffs (Berkelmans \& van Oppen 2006, Cantin et al. 2009).

\section{Site differences in symbiont communities in Kenya}

The significant interaction between genus and site, combined with the results of the regression analysis against temperature variables, indicates that sitespecific temperature regime plays an important role in determining differences in symbiont communities. Although all sites have similar mean temperatures (ranging from 27.3 to $27.6^{\circ} \mathrm{C}$; Fig. 1), tidal variability at each of the 4 sites results in localized heating and cooling over short time scales as a result of restricted water exchange between the lagoons and the fore reef; this results in considerable differences in temperature variability between sites.

Kanamai had the highest frequency of colonies containing clade D Symbiodinium and had the highest mean annual maximum water temperatures over the study period $\left(33.9^{\circ} \mathrm{C}\right)$, lowest mean annual minimum temperatures $\left(23.8^{\circ} \mathrm{C}\right)$, and highest standard deviation $\left(1.8^{\circ} \mathrm{C}\right)$ (see Fig. 1B). Kanamai also had the highest positive skewness (i.e. a long right-hand tail in the temperature distribution, indicating rare but extremely high temperatures) and was the most leptokurtic site (positive kurtosis in the temperature distribution, indicating a narrow peak around the mean and fatter tails to the distribution, see Table 1). 
In contrast, Mombasa had the lowest incidence of clade D and had the lowest annual maximum temperature $\left(31.1^{\circ} \mathrm{C}\right)$, highest minimum temperature $\left(24.6^{\circ} \mathrm{C}\right)$, and lowest standard deviation $\left(1.2^{\circ} \mathrm{C}\right)$ (see Fig. 1B). It had the lowest positive skewness (i.e. fewer occurrences of extreme high temperatures) and was one of the most platykurtic sites (negative kurtosis, indicating wider peaks in the temperature distribution and thinner tails in the distribution, see Table 1).

Together, these data suggest that no single temperature metric determines the relative frequency of clade D in reef corals among different sites. Instead, the overall temperature regime drives the abundance of clade $\mathrm{D}$, with high maximum temperatures, high variability, high positive skewness, and leptokurtosis all helping to drive the relative frequency of clade D. In this study, low minimum temperatures were also associated with a high frequency of clade D, but this was likely to be an artifact of high variability; low minimum temperatures without high maximum temperatures are probably unlikely to drive the clade D found in Kenya (but see Chen et al. 2003 for an unusual clade D commonly found in subtropical Taiwan).

Temperatures obtained using in situ gauges differed significantly from temperatures obtained from satellites, and were much better at predicting the frequency of clade D (results not shown). Satellitederived data may not be able to capture the rapid temperature fluctuations caused by tidal variability at the study sites, or distinguish lagoonal study sites from the open ocean. This suggests that the low temporal and spatial resolution of satellite data may limit their utility for interpreting Symbiodinium distributions, except when used to explain patterns over larger (regional) scales.

\section{Changes in symbiont communities over time}

There was no sustained directional change in the relative abundance of clades C and D in Kenya over the period 2000 to 2010 . However, during the first half of the study (2000 to 2004) colonies containing mixed communities of $\mathrm{C}+\mathrm{D}$ were relatively frequent, whereas in the second half of the study (2005 to 2010) mixed colonies were rare, occurring only in 2009. The resolution of DGGE limits the detection of symbionts unless they represent at least 5 to $10 \%$ of the total community (Thornhill et al. 2006, LaJeunesse et al. 2008), and it is likely that more colonies contained mixed communities than were detected in this study (Baker \& Romanski 2007, Silverstein et al. 2012). Nevertheless, the fact that clade D symbionts were detected in mixed communities from 2000 to 2004, but became rare afterwards, indicates that they may have fallen below threshold limits in the latter half of the study. This suggests that the changes in the relative frequency of clade $D$ in this study are the result of shuffling of pre-existing symbiont communities (Baker 2003, Stat et al. 2006).

One hypothesis why mixed communities were relatively common from 2000 to 2004 is that these corals were still recovering from the effects of the 1998 bleaching. If some of the colonies that survived 1998 experienced increases in clade D, as has previously been suggested (Baker et al. 2004), the disappearance of mixed communities by 2005 may indicate that these increases were sustained for as long as 6 yr following the event. It is also notable that the single incidence of Porites dominated by clade D occurred early in the study (August 2001), which may have been an effect of the 1998 bleaching. There is also some evidence for a brief increase in clade D in 2005 that was lost again from 2006 to 2008 before another spike in clade D occurred in 2009 to 2010. Bleaching was observed at these study sites in 2005, but did not lead to high mortality (T. McClanahan pers. obs.). These patterns were more apparent in Pocillopora and Pavona from Kanamai and Diani, but were absent from Mombasa, suggesting that temperature regimes at Kanamai and Diani may have favored increases in clade D during those years.

Symbiont communities on shallow Kenyan reefs appear relatively dynamic, and unidirectional shifts to favor particular symbionts were rarely maintained over multiple years, given that the prevailing temperature regime is determined by short-term tidal variability that varies among sites. Indeed, sitespecific tidal variation in temperature overrides any climate signal in our 2000 to 2010 data, although there is a possibility of longer term interactions with episodic ocean-atmosphere oscillations, such as the El Niño-Southern Oscillation and the Indian Ocean Dipole.

Our data suggest that any disturbance that affects the temperature metrics investigated here is likely to affect the distribution of Symbiodinium in clade D. Consequently, the composition of symbiont communities, and their dynamics, cannot be explained solely as the result of acute disturbance (Baker et al. 2004) or by long-term environmental conditions (LaJeunesse et al. 2010). Instead, both acute and chronic stressors caused by oceanographic and tidal 
oscillations interact with taxa to produce highly dynamic symbiotic communities on Kenyan reefs. High maximum temperatures and high variability allow clade $\mathrm{D}$ to be maintained at relatively high levels in Kenya, although its relative abundance varied significantly from year to year because tidal variability causes frequent stress periods that are likely to disrupt these communities over lunar time scales. Since the immediate effects of tidal variability are far greater than those of climate warming, the emergent picture is one in which gradual changes in symbiont communities as a result of warming are masked by larger changes over shorter timescales.

These results contrast with, and complement, monitoring studies in other areas. In Panama extreme temperature fluctuations do not occur, despite high tidal ranges, because reef geomorphology still allows water exchange. Consequently, intra-annual disruptions are infrequent, and gradual changes in symbiont communities following acute disturbance, such as the 1997/1998 El Niño, are more detectable (A. C. Baker et al. unpubl. data). In Barbados, annual maximum temperatures are moderate and temperature variation is low; therefore, transient spikes in clade D following bleaching are not maintained (LaJeunesse et al. 2009). In the Florida Keys and Bahamas temperatures are also moderate, but variability is higher than in Barbados (but less extreme than the tidal fluctuations found in Kenya); consequently, clade D is maintained short term but cannot persist in the absence of further bleaching or other acute disturbance (Thornhill et al. 2006).

This perspective suggests that Symbiodinium in clade D are not inherently opportunistic (LaJeunesse et al. 2009, Stat \& Gates 2011) and might be capable of long-term persistence on reefs if conditions permit. However, the environmental niche that supports these symbionts is rarely maintained on most Kenyan reefs. Periodic disruptions due to mass bleaching will increase the relative abundance of clade $\mathrm{D}$, and warming baselines may tend to increase the longevity of these shifts, but not all bleaching events will lead to dramatic or sustained changes in symbiont communities, since equilibrium conditions will quickly select against these symbionts once conditions return to normal. Although host effects will also contribute significantly to thermal tolerance, these results provide one mechanistic basis for the observation that corals from warm yet variable conditions are the best able to survive climate change (McClanahan et al. 2007, Oliver \&
Palumbi 2011), and support assessments of thermal regime as a means of economically identifying conservation priority sites in anticipation of continued climate change.

Acknowledgements. The Wildlife Conservation Society supported the research through grants from the Western Indian Ocean Marine Science Association MASMA program, and the Tiffany \& Co. Foundation. A.C.B. and R.K.B. were also supported by the Lenfest Ocean Program. H. Wirshing and P. Jones provided laboratory assistance, and J. Maina assisted with obtaining the NOAA temperature data. The Kenyan Ministry of Science and Technology provided research clearance, and Kenya Wildlife Services provided the CITES permit.

\section{LITERATURE CITED}

Baird AH, Cumbo VR, Leggat W, Rodriguez-Lanetty M (2007) Fidelity and flexibility in coral symbioses. Mar Ecol Prog Ser 347:307-309

Baird AH, Bhagooli R, Ralph PJ, Takahashi S (2009) Coral bleaching: the role of the host. Trends Ecol Evol 24:16-20

Baker AC (2003) Flexibility and specificity in coral-algal symbiosis: diversity, ecology and biogeography of Symbiodinium. Annu Rev Ecol Evol Sits 34:661-689

Baker AC, Romanski AM (2007) Multiple symbiotic partnerships are common in scleractinian corals, but not in octocorals: comment on Goulet (2006). Mar Ecol Prog Ser 335:237-242

Baker AC, Rowan R, Knowlton N (1997) Symbiosis ecology of two Caribbean acroporid corals. In: Proceedings of the 8th International Coral Reef Symposium, Vol 2. Smithsonian Tropical Research Institute, Panama, p 1295-1300

Baker AC, Starger CJ, McClanahan TR, Glynn PW (2004) Corals' adaptive response to climate change. Nature 430:741

Berkelmans R, van Oppen MJH (2006) The role of zooxanthellae in the thermal tolerance of corals: a 'nugget of hope' for coral reefs in an era of climate change. Proc Biol Sci 273:2305-2312

> Cantin NE, van Oppen MJH, Willis BL, Mieog JC, Negri AP (2009) Juvenile corals can acquire more carbon from high-performance algal symbionts. Coral Reefs 28: 405-414

Chen CA, Lam KK, Nakano Y, Tsai WS (2003) A stable association of the stress-tolerant zooxanthellae, Symbiodinium clade $\mathrm{D}$, with the low-temperature-tolerant coral, Oulastrea crispata (Scleractinia: Faviidae) in subtropical non-reefal coral communities. Zool Stud 42: 540-550

> Correa AMS, Baker AC (2009) Understanding diversity in coral-algal symbiosis: a cluster-based approach to interpreting fine-scale genetic variation in the genus Symbiodinium. Coral Reefs 28:81-93

Correa AMS, McDonald MD, Baker AC (2009) Development of clade-specific Symbiodinium primers for quantitative PCR (qPCR) and their application to detecting heat tolerant symbionts in Caribbean corals. Mar Biol 156: 2403-2411 
Cunning R, Baker AC (2013) Excess symbionts increase the susceptibility of reef corals to bleaching. Nat Clim Change 3:259-262

Fitt WK, Gates RD, Hoegh-Guldberg O, Bythell JC and others (2009) Response of two species of Indo-Pacific corals, Porites cylindrica and Stylophora pistillata, to short-term thermal stress: The host does matter in determining the tolerance of corals to bleaching. J Exp Mar Biol Ecol 373:102-110

Gates RD, Edmunds PJ (1999) The physiological mechanisms of acclimatization in tropical reef corals. Am Zool 39:30-43

Glynn PW, Maté JL, Baker AC, Calderón MO (2001) Coral bleaching and mortality in Panamá and Ecuador during the 1997-1998 El Niño-Southern Oscillation event: spatial/temporal patterns and comparisons with the 1982-1983 event. Bull Mar Sci 69:79-109

> Hoegh-Guldberg O, Bruno JF (2010) The impact of climate change on the world's marine ecosystems. Science 328: 1523-1528

> Hoegh-Guldberg O, Mumby PJ, Hooten AJ, Steneck RS and others (2007) Coral reefs under rapid climate change and ocean acidification. Science 318:1737-1742

Jones AM, Berkelmans R (2011) Tradeoffs to thermal acclimation: energetics and reproduction of a reef coral with heat tolerant Symbiodinium type D. J Mar Biol 2011: 185890

Jones AM, Berkelmans R, Van Oppen MJH, Mieog JC, Sinclair W (2008) A community change in the algal endosymbionts of a scleractinian coral following a natural bleaching event: field evidence of acclimatization. Proc R Soc Lond B 275:1359-1365

- LaJeunesse TC (2001) Investigating the biodiversity, ecology and phylogeny of endosymbiotic dinoflagellates in the genus Symbiodinium using the ITS region: in search of a 'species' level marker. J Phycol 37:866-880

> LaJeunesse TC (2002) Diversity and community structure of symbiotic dinoflagellates from Caribbean coral reefs. Mar Biol 141:387-400

> LaJeunesse TC, Bonilla HR, Warner ME, Wills M, Schmidt GW, Fitt WK (2008) Specificity and stability in high latitude eastern Pacific coral-algal symbioses. Limnol Oceanogr 53:719-727

> LaJeunesse TC, Smith RT, Finney J, Oxenford H (2009) Outbreak and persistence of opportunistic symbiotic dinoflagellates during the 2005 Caribbean mass coral 'bleaching' event. Proc Biol Sci 276:4139-4148

> LaJeunesse TC, Pettay DT, Sampayo EM, Phongsuwan N and others (2010) Long-standing environmental conditions, geographic isolation and host-symbiont specificity influence the relative ecological dominance and genetic diversification of coral endosymbionts in the genus Symbiodinium. J Biogeogr 37:785-800

LaJeunesse TC, Parkinson JE, Reimer JD (2012) A geneticsbased description of Symbiodinium minutum sp. nov. and $S$. psygmophilum sp. nov. (Dinophyceae), two dinoflagellates symbiotic with Cnidaria. J Phycol 48(6): 1380-1391

Little AF, Van Oppen MJH, Willis BL (2004) Flexibility in algal endosymbioses shapes growth in reef corals. Science 304:1492-1494

> McClanahan TR (1988) Seasonality in East Africa's coastal waters. Mar Ecol Prog Ser 44: 191-199

McClanahan TR, Maina J (2003) Response of coral assem- blages to the interaction between natural temperature variation and rare warm-water events. Ecosystems 6: 551-563

McClanahan TR, Ateweberhan M, Muhando CA, Maina J, Mohammed MS (2007) Effects of climate and seawater temperature variation on coral bleaching and mortality. Ecol Monogr 77:503-525

> Mieog JC, Van Oppen MJH, Berkelmans R, Stam WT, Olsen JL (2009) Quantification of algal endosymbionts (Symbiodinium) in coral tissue using real-time PCR. Molec Ecol Resour 9:74-82

Oliver TA, Palumbi SR (2009) Distributions of stress-resistant coral symbionts match environmental patterns at local but not regional scales. Mar Ecol Prog Ser 378: 93-103

> Oliver TA, Palumbi SR (2011) Do fluctuating temperature environments elevate coral thermal thresholds? Coral Reefs 30:429-440

> Rosenberg E, Koren O, Reshef L, Efrony R, Zilber-Rosenberg I (2007) The role of microorganisms in coral health, disease and evolution. Nat Rev Microbiol 5:355-362

Rowan R (2004) Thermal adaptation in reef coral symbionts. Nature 430:742

Rowan R, Knowlton N (1995) Intraspecific diversity and ecological zonation in coral-algal symbiosis. Proc Natl Acad Sci USA 92:2850-2853

> Rowan R, Powers DA (1991) Molecular genetic identification of symbiotic dinoflagellates (zooxanthellae). Mar Ecol Prog Ser 71:65-73

- Rowan R, Knowlton N, Baker AC, Jara J (1997) Landscape ecology of algal symbiont communities explains variation in episodes of coral bleaching. Nature 388:265-269

Sall, J, Lehman A, Creighton L (2001) JMP Start Statistics: a guide to statistics and data analysis using JMP and JMP IN Software. Duxbury, CA

Sampayo EM, Dove S, LaJeunesse TC (2009) Cohesive molecular genetic data delineate species diversity in the dinoflagellate genus Symbiodinium. Mol Ecol 18(3): 500-519

Savage AM, Trapido-Rosenthal H, Douglas AE (2002) On the functional significance of molecular variation in Symbiodinium, the symbiotic algae of Cnidaria: photosynthetic response to irradiance. Mar Ecol Prog Ser 244: $27-37$

Seutin G, White BN, Boag PT (1991) Preservation of avian blood and tissue samples for DNA analyses. Can J Zool 69:82-90

Silverstein RN, Correa AMS, Baker AC (2012) Specificity is rarely absolute in coral-algal symbiosis: implications for coral response to climate change. Proc R Soc Lond B 275: 1359-1365

Stat M, Gates RD (2011) Clade D Symbiodinium in scleractinian corals: A 'nugget' of hope, a selfish opportunist, an ominous sign, or all of the above? J Mar Biol 730715:1-9

Stat M, Carter D, Hoegh-Guldberg O (2006) The evolutionary history of Symbiodinium and scleractinian hostssymbiosis, diversity, and the effect of climate change. Perspect Plant Ecol Evol Syst 8:23-43

Stat M, Loh WKW, LaJeunesse TC, Hoegh-Guldberg O, Carter DA (2009a) Stability of coral-endosymbiont associations during and after a thermal stress event in the southern Great Barrier Reef. Coral Reefs 28:709-713

Stat M, Pochon X, Cowie ROM, Gates RD (2009b) Specificity in communities of Symbiodinium in corals from Johnston 
Atoll. Mar Ecol Prog Ser 386:83-96

Stat M, Bird CE, Pochon X, Chasqui L and others (2011) Variation in Symbiodinium ITS2 sequence assemblages among coral colonies. PLoS ONE 6:e15854

Tchernov D, Gorbunov MY, de Vargas C, Narayan Yadav S, Milligan AJ, Häggblom M, Falkowski PG (2004) Membrane lipids of symbiotic algae are diagnostic of sensitivity to thermal bleaching in corals. Proc Nat Aca Sci USA 101:13531-13535

Thornhill DJ, Fitt WK, Schmidt GW (2006a) Highly stable

Editorial responsibility: Peter Edmunds,

Northridge, California, USA symbioses among western Atlantic brooding corals. Coral Reefs 25:515-519

Thornhill DJ, LaJeunesse TC, Kemp DW, Fitt WK, Schmidt GW (2006b) Multi-year, seasonal genotypic surveys of coral-algal symbioses reveal prevalent stability or postbleaching reversion. Mar Biol 148:711-722

Toller WW, Rowan R, Knowlton N (2001) Repopulation of zooxanthellae in the Caribbean corals Montastraea annularis and $M$. faveolata following experimental and disease-associated bleaching. Biol Bull 201:360-373

Submitted: March 12, 2012; Accepted: October 7, 2012 Proofs received from author(s): March 19, 2013 